\title{
Dental disease and risk of coronary heart disease and mortality
}

\author{
Frank DeStefano, Robert F Anda, Henry S Kahn, David F Williamson, Carl M Russell
}

Abstract

Objective-To investigate a reported association between dental disease and risk of coronary heart disease.

Setting-National sample of American adults who participated in a health examination survey in the early 1970s.

Design-Prospective cohort study in which participants underwent a standard dental examination at baseline and were followed up to 1987 . Proportional hazards analysis was used to estimate relative risks adjusted for several covariates.

Main outcome measures-Incidence of mortality or admission to hospital because of coronary heart disease; total mortality.

Results-Among all 9760 subjects included in the analysis those with periodontitis had a $25 \%$ increased risk of coronary heart disease relative to those with minimal periodontal disease. Poor oral hygiene, determined by the extent of dental debris and calculus, was also associated with an increased incidence of coronary heart disease. In men younger than 50 years at baseline periodontal disease was a stronger risk factor for coronary heart disease; men with periodontitis had a relative risk of $1 \cdot 72$. Both periodontal disease and poor oral hygiene showed stronger associations with total mortality than with coronary heart disease.

Conclusion-Dental disease is associated with an increased risk of coronary heart disease, particularly in young men. Whether this is a causal association is unclear. Dental health may be a more general indicator of personal hygiene and possibly health care practices.

Department of Epidemiology and Biostatistics, Marshfield Medical Research Foundation, Marshfield, WI 54449-5790, USA Frank DeStefano, epidemiologist

National Center for Chronic Disease Prevention and Health Promotion, Centers for Disease Control, Atlanta, GA 30333

Robert F Anda,

epidemiologist

David F Williamson, epidemiologist

Carl M Russell, statistician

Department of Community and Preventive Medicine, Emory University School of Medicine, Atlanta, GA 30333-3219 Henry S Kahn, associate professor

Correspondence to: Dr DeStefano.

\section{Introduction}

In 1989 Mattila et al reported the results of a casecontrol study in which they found a strong association between dental disease and acute myocardial infarction.' Using an index based on severity of caries, periodontitis, periapical lesions, and pericoronitis they found that patients admitted to hospital for acute myocardial infarction had higher scores on the dental index than matched controls from the population. Given the distribution of scores among their controls, we estimate that people above the upper quartile had at least a twofold higher risk of being admitted to hospital for acute myocardial infarction than did people with a score of zero. This is comparable to the increase of well established risk factors for coronary heart disease, such as cigarette smoking, hypercholesterolaemia, and hypertension. ${ }^{2}$

Adults in the United States have an average of 10 to 17 decayed, missing, or filled teeth and most have experienced periodontal disease (gingivitis or periodontitis), with moderate to severe periodontal disease being present in one third of the elderly population. ${ }^{34}$ Thus the impact of an increased risk of coronary heart disease associated with poor dental health could be substantial. Because of the potential importance of the association, as well as to overcome methodological limitations of the original study, ${ }^{156}$ we analysed data from a prospective study that allowed us to assess the association between dental disease and coronary heart disease.

\section{Subjects and methods}

We analysed data from the national health and nutrition examination study I and its epidemiological follow up study..$^{7-9}$ From 1971 to 1974, 20749 subjects were examined in the initial study. The follow up study was restricted to participants from the first study who were 25 to 74 years of age at baseline. All subjects were followed up in 1982. In 1985 only those aged 55 and older at baseline were studied, and in 1986-7 all subjects were followed up again. Information for the follow up study was collected by means of personal interviews, death certificates, and records from hospitals and nursing homes. Over $90 \%$ of the study population was successfully traced, with a median follow up of 14 years.

During the baseline examinations the subjects underwent a standardised dental examination. For our analysis we used four measures of dental disease.

(1) Number of decayed permanent teeth.

(2) Periodontal classification: no periodontal disease; gingivitis (with or without pockets); periodontitis (grade 4+ pockets); and no teeth.

(3) Periodontal index. Each tooth was given a score of $0,1,2,6$, or 8 depending on the degree of periodontal disease; the index was the arithmetic average of all the teeth that were scored.

(4) Oral hygiene index. Selected surfaces of six teeth were examined and scored for extent of debris and calculus. The amount of debris was scored as 0 to 3 for each tooth surface depending on the extent to which soft debris or stain covered a tooth surface. The amount of calculus was also scored on a scale of 0 to 3 for each tooth surface depending on the degree of supragingival or subgingival calculus covering the tooth surface. The debris scores were totalled and divided by the number of surfaces scored to obtain the debris index. The calculus index was determined similarly. The oral hygiene index was calculated as the sum of the debris and calculus indices.

We used Cox proportional hazards models to compare the incidence of coronary heart disease and total mortality according to the state of dental health at baseline while at the same time controlling for several potential confounding variables. ${ }^{10}$ We checked the assumption of proportionality by using graphs of the $\log -\log$ survivor function. We excluded from the analysis subjects who had a history of heart attack, heart failure, stroke, cancer, or an unknown periodontal classification at baseline. The end points of coronary heart disease we evaluated were mortality (underlying cause of death on the death certificate coded as 410-414 according to ICD ninth revision) and admission to hospital (first admission with discharge diagnoses coded 410-414).

The incidence of coronary heart disease was the primary outcome measure in our analyses. If a person had been admitted to hospital for coronary heart disease we used the date of first admission as the incidence date. If a person died of coronary heart disease but was never admitted to hospital we used the 
date of death as the incidence date. In addition to the incidence of coronary heart disease we also evaluated associations with total mortality.

In the proportional hazards models we included the potentially confounding variables of age, sex, race, education, marital state, systolic blood pressure, total cholesterol concentration, body mass index, diabetes, physical activity, alcohol consumption, poverty index, and cigarette smoking. The poverty index is the ratio of the total income of the household and a multiple of the total income necessary to maintain a family with given characteristics on a nutritionally adequate food plan. During the baseline examinations only a subsample was asked about history of smoking. Therefore, we used the categories current smoker, former smoker, never a smoker, and unknown in our analyses. We performed additional analyses restricted to subjects whose history of smoking was known at baseline.

Our main analyses were of men and women who were aged 25 to 74 at the baseline examinations. As nearly all of the subjects in the study by Mattila et al were men aged 50 to 60 or younger, we also present results for men who were under 50 at the baseline examinations. The subjects in Mattila's study had all been admitted to hospital for acute myocardial infarction. Therefore we performed additional analyses

TABLE I-Baseline characteristics by periodontal classification in men and women aged 25-74. Figures are numbers (percentages)

\begin{tabular}{|c|c|c|c|c|}
\hline \multirow[b]{2}{*}{ Characteristic } & \multicolumn{4}{|c|}{ Periodontal class } \\
\hline & $\begin{array}{l}\text { No disease } \\
(\mathrm{n}=3542)\end{array}$ & $\begin{array}{l}\text { Gingivitis } \\
(\mathrm{n}=2282)\end{array}$ & $\begin{array}{l}\text { Periodontitis } \\
(n=1786)\end{array}$ & $\begin{array}{c}\text { No teeth } \\
(n=2150)\end{array}$ \\
\hline Women & $2446(69 \cdot 1)$ & $1387(60 \cdot 8)$ & $864(48 \cdot 4)$ & $1276(59 \cdot 4)$ \\
\hline Men & $1096(30.9)$ & $895(39 \cdot 2)$ & $922(51 \cdot 6)$ & $874(40.6)$ \\
\hline \multicolumn{5}{|l|}{ Age (years): } \\
\hline $25-34$ & $1294(36 \cdot 5)$ & $778(34 \cdot 1)$ & $216(12 \cdot 1)$ & $95(4 \cdot 4)$ \\
\hline $35-44$ & $981(27 \cdot 7)$ & $602(26 \cdot 4)$ & $355(19.9)$ & $207(9 \cdot 6)$ \\
\hline $45-54$ & $518(14 \cdot 6)$ & $338(14 \cdot 8)$ & $339(18.9)$ & $245(11 \cdot 4)$ \\
\hline $55-64$ & $275(7 \cdot 7)$ & $213(9 \cdot 3)$ & $241(13.5)$ & $345(16 \cdot 0)$ \\
\hline $65-74$ & $474(13 \cdot 4)$ & $351(15 \cdot 4)$ & $635(35.6)$ & $1257(58.5)$ \\
\hline White & $3156(89 \cdot 1)$ & $1777(77.9)$ & $1269(71 \cdot 0)$ & $1839(85 \cdot 5)$ \\
\hline \multicolumn{5}{|c|}{ 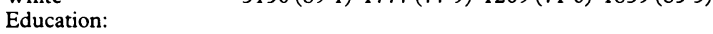 } \\
\hline$<$ High school & $988(28 \cdot 1)$ & $968(42 \cdot 8)$ & 1078 & $1525(71 \cdot 6)$ \\
\hline \multicolumn{5}{|l|}{ High school } \\
\hline graduates & $1358(38.6)$ & $815(36 \cdot 0)$ & $430(24 \cdot 3)$ & $435(20 \cdot 4)$ \\
\hline$>$ Higher education & $1173(33 \cdot 3)$ & $479(21 \cdot 2)$ & $261(14 \cdot 8)$ & $170(8 \cdot 0)$ \\
\hline Currently married & $2839(80 \cdot 2)$ & $1757(77 \cdot 0)$ & $1280(71 \cdot 7)$ & $1474(68 \cdot 6)$ \\
\hline \multicolumn{5}{|l|}{ Smoking: } \\
\hline Never & $562(15 \cdot 9)$ & $342(15 \cdot 0)$ & $223(12 \cdot 5)$ & $299(13.9)$ \\
\hline Former & $243(6 \cdot 9)$ & $145(6 \cdot 4)$ & $120(6 \cdot 7)$ & $167(7 \cdot 7)$ \\
\hline Current & $358(10 \cdot 1)$ & $310(13.6)$ & $286(16 \cdot 0)$ & $251(11 \cdot 7)$ \\
\hline Unknown & $2379(67 \cdot 2)$ & $1485(65 \cdot 1)$ & $1157(64 \cdot 8)$ & $1433(66 \cdot 6)$ \\
\hline Diabetes & $80(2 \cdot 3)$ & $68(3.0)$ & $96(5 \cdot 4)$ & $168(7 \cdot 8)$ \\
\hline High blood pressure & $564(15 \cdot 9)$ & $443(19 \cdot 4)$ & $467(26 \cdot 1)$ & $680(31 \cdot 6)$ \\
\hline
\end{tabular}

TABLE II-Deaths and coronary heart disease by periodontal classification in men and women aged 25-74 years. Figures are numbers (percentages)

\begin{tabular}{lcccc}
\hline & \multicolumn{4}{c}{ Periodontal class } \\
\cline { 2 - 5 } Outcome & $\begin{array}{c}\text { No disease } \\
(\mathrm{n}=3542)\end{array}$ & $\begin{array}{c}\text { Gingivitis } \\
(\mathrm{n}=2282)\end{array}$ & $\begin{array}{c}\text { Periodontitis } \\
(\mathrm{n}=1786)\end{array}$ & $\begin{array}{c}\text { No teeth } \\
(\mathrm{n}=2150)\end{array}$ \\
\hline Death (any cause) & $345(9 \cdot 7)$ & $318(13.9)$ & $556(31 \cdot 1)$ & $877(40 \cdot 8)$ \\
Death from coronary heart disease & $92(2 \cdot 6)$ & $93(4 \cdot 1)$ & $151(8 \cdot 4)$ & $255(11 \cdot 9)$ \\
Admission to hospital for coronary heart disease & $231(6.5)$ & $170(7 \cdot 4)$ & $258(14 \cdot 4)$ & $413(19 \cdot 2)$ \\
Death from or admission for coronary heart disease & $288(8 \cdot 1)$ & $232(10 \cdot 2)$ & $349(19 \cdot 5)$ & $556(25 \cdot 9)$ \\
\hline
\end{tabular}

TABLE III-Adjusted relative risks (95\% confidence intervals) ${ }^{*}$ of death from coronary heart disease or admission to hospital and total mortality associated with selected indicators of oral health in men and women aged 25-74

\begin{tabular}{lcll}
\hline Indicator & No of subjects $\dagger$ & $\begin{array}{c}\text { Coronary heart } \\
\text { disease }\end{array}$ & Total mortality \\
\hline $\begin{array}{l}\text { Periodontal class: } \\
\text { No disease }\end{array}$ & 3367 & 1.00 & \\
$\quad$ Gingivitis & 2170 & $1.05(0.88$ to 1.26$)$ & 1.00 \\
$\quad$ Periodontitis & 1674 & $1.25(1.06$ to 1.48$)$ & $1.46(1.26$ to 1.44$)$ \\
No teeth & 2031 & $1.23(1.05$ to 1.44$)$ & $1.46(1.27$ to 1.67$)$ \\
Periodontal index (per unit) & 7211 & $1.04(1.01$ to 1.08$)$ & $1.09(1.06$ to 1.12$)$ \\
Oral hygiene index (per unit) & 6467 & $1.12(1.06$ to 1.20$)$ & $1.15(1.09$ to 1.21$)$ \\
\hline
\end{tabular}

${ }^{\star}$ Adjusted for age, sex, race, education, poverty index, marital state, systolic blood pressure, total cholesterol *Adjusted for age, sex, race, education, poverty index, marital state, systolic blood pressure, total cholesterol
concentration, diabetes, body mass index, physical activity, alcohol consumption, and cigarette smoking.

tExcluding those with missing data for any variable and, for periodontal index and hygiene index, those who had no teeth. focusing on acute myocardial infarction (ICD (ninth revision) code 410 ). The results for acute myocardial infarction were generally similar to those for total coronary heart disease and are not reported separately, although in men younger than 50 the log-log survival curves by periodontal disease tended to converge as duration of follow up increased.

\section{Results}

The baseline characteristics of the subjects varied according to severity of periodontal disease (table I). Subjects with more severe disease were more likely to be men, older, non-white, less educated, unmarried, and smokers. Although the proportion of people who reported having diabetes or high blood pressure increased as severity of periodontal disease increased, some of the increase may be a reflection of the older ages of those with more severe disease. As would be expected, those without teeth at baseline were older than those who had teeth, regardless of periodontal class.

The proportion of subjects with coronary heart disease or who died during follow up was also related to periodontal class (table II). Total mortality and each of the outcomes of coronary heart disease increased as severity of periodontal disease increased. The highest proportions for each of the outcomes were seen among those who had no teeth at baseline, although differences in age contributed to these results.

In proportional hazards models in which we adjusted for age and several other potential confounders the severity of periodontal disease had a small effect on the risk of coronary heart disease (table III). Gingivitis did not increase the risk of coronary heart disease, whereas periodontitis or having no teeth increased it by about $25 \%$. When the periodontal index was used as a continuous measure of periodontal disease the relative risk was 1.04 per unit increase in the index. This means that those with the highest periodontal index score of 8 had a relative risk of 1.43 compared with those with a score of 0 , and those at the 90th centile of the distribution of the periodontal index $($ score $=5)$ had a relative risk of 1.25 compared with those below the lowest decile (score $=0$ ).

High scores on the oral hygiene index carried a greater risk of coronary heart disease than on the periodontal index (table III). People with a maximum hygiene index score of 6 had a relative risk of 2.03 compared with those with an index of 0 , and those at the 90 th centile (score $=3$ ) were 1.42 times more likely to experience a coronary heart disease event than were those below the lowest decile (score $=0$ ). The amount of dental debris (relative risk $=1 \cdot 24$ ) and calculus (relative risk $=1 \cdot 19$ ) contributed equally to the increased risk associated with the hygiene index. The number of decayed permanent teeth did not alter the risk of coronary heart disease (relative risk $=0.99,95 \%$ confidence interval 0.96 to 1.03 ).

When we restricted the analyses to subjects whose history of smoking was known the results were similar to the results among all subjects. When no periodontal disease was used as the referent category the adjusted relative risks for coronary heart disease were $0.79(0.58$ to 1.08$)$ for gingivitis, $1.29(0.87$ to 1.70$)$ for periodontitis, and $1.33(1.02$ to 1.73$)$ for no teeth. The adjusted relative risks were $1.06(1.01$ to 1.12$)$ for the periodontal index and $1.13(0.95$ to 1.26$)$ for the oral hygiene index.

The severity of periodontal disease increased the risk of total mortality more than the risk of coronary heart disease (table III). Compared with subjects with little or no periodontal disease, those with gingivitis were at about $23 \%$ higher risk, and those with periodontitis or who had no teeth were at about $50 \%$ higher risk of 
TABLE IV-Adjusted relative risks (95\% confidence intervals)* of death from coronary heart disease or admission to hospital and total mortality associated with selected indicators of oral health in men aged 25-49

\begin{tabular}{lccc}
\hline Indicator & No of subjectst & $\begin{array}{c}\text { Coronary heart } \\
\text { disease }\end{array}$ & Total mortality \\
\hline Periodontal class: & & & \\
$\quad$ No disease & 673 & 1.00 & 1.00 \\
Gingivitis & 529 & $0.98(0.63$ to 1.54$)$ & $1.42(0.84$ to 2.42$)$ \\
$\quad$ Periodontitis & 300 & $1.72(1.10$ to 2.68$)$ & $2.12(1.24$ to 3.62$)$ \\
$\quad$ No teeth & 92 & $1.71(0.93$ to 3.15$)$ & $2.60(1.33$ to 5.07$)$ \\
Periodontal index (per unit) & 1502 & $1.09(1.00$ to 1.19$)$ & $1.11(1.01$ to 1.22$)$ \\
Oral hygiene index (per unit) & 1436 & $1.11(0.96$ to 1.27$)$ & $1.23(1.06$ to 1.43$)$ \\
\hline
\end{tabular}

${ }^{\star}$ Adjusted for age, sex, race, education, poverty index, marital state, systolic blood pressure, total cholesterol concentration, diabetes, body mass index, physical activity, alcohol consumption, and cigarette smoking.

tExcluding those with missing data for any variable and, for periodontal index and hygiene index, those who had no teeth.

dying during follow up. The association of periodontal index and total mortality reflects the findings of the periodontal classification; the relative risk was 1.53 for those at the 90 th centile compared with those below the lowest decile of the distribution of the index. The oral hygiene index carried about the same level of increased risk for total mortality as for the incidence of coronary heart disease.

When we restricted the analysis to men under 50 at baseline we found a stronger association between periodontal disease and coronary heart disease (table IV). Men with periodontitis or who had no teeth were about $70 \%$ more likely to have coronary heart disease than were men with no periodontal disease. Among men with periodontitis the relative risk of death from coronary heart disease $(2 \cdot 86)$ was greater than the relative risk of being admitted to hospital for coronary heart disease $(1.58)$. A similar difference in relative risks of death from coronary heart disease (3.71) and admission to hospital $(1 \cdot 46)$ was seen among those who had no teeth.

Among men under 50 at baseline the periodontal index increased the risk of death from coronary heart disease or admission to hospital (1.09 per unit increase in the index) (table IV), with a maximum relative risk of $2 \cdot 00$. A unit increase in the oral hygiene index was associated with a $1 \cdot 12$-fold increased risk of coronary heart disease in younger men.

The number of decayed permanent teeth did not show any association with risk of coronary heart disease among younger men (relative risk $=1.01,0.94$ to $1 \cdot 10$ ).

Results from analyses restricted to men younger than 50 at baseline whose history of smoking was known were in line with the preceding results. With no periodontal disease as the referent category, the adjusted relative risks for coronary heart disease were $0.93(0.49$ to 1.75$)$ for gingivitis, $1.54(0.80$ to 2.96$)$ for periodontitis, and $2.99(1.28$ to 6.98$)$ for no teeth. The adjusted relative risks were $1.07(0.94$ to 1.22$)$ for the periodontal index and $1.05(0.85$ to 1.29$)$ for the oral hygiene index.

The strongest associations we found were between measures of periodontal disease or oral hygiene and total mortality among men under 50 at baseline (table IV). Men with periodontitis had more than a twofold increased risk of dying compared with men who had no periodontal disease at baseline. Young men who had no teeth at baseline had a $2 \cdot 6$-fold increased risk of dying. For the periodontal index the results reflected the findings with the periodontal classification. The oral hygiene index also showed a stronger association with total mortality than with the outcome of coronary heart disease in young men. Young men who had a maximum oral hygiene index of 6 had a risk of dying 3.4 times higher than those who had a hygiene index of 0 .

\section{Discussion}

Overall we found that periodontal disease was associated with a small increased risk of coronary heart disease. In men under 50, however, periodontal disease was a stronger risk factor; men with periodontitis had a nearly twofold higher risk of coronary heart disease than men who had little or no periodontal disease. In the total population the degree of dental debris and calculus, as reflected in the oral hygiene index, was a stronger risk factor for coronary heart disease than was the severity of periodontal disease. In both the total population and among younger men periodontal disease and oral hygiene were more strongly associated with total mortality than with the incidence of coronary heart disease.

Although providing support for the findings of Mattila et al, our results show a weaker association between dental disease and coronary heart disease. For example, in Mattila's study the highest score on the dental index carried a 10 -fold increased risk of acute myocardial infarction relative to the lowest score. Among the younger men in our study the maximum relative risk for coronary heart disease was about $2 \cdot 0$ for both the periodontal index and the oral hygiene index. The dental index in the study by Mattila et al was composed of both severity of periodontal disease and dental caries, suggesting that dental decay may contribute to the risk of coronary heart disease. We found no association between extent of active dental decay and risk of coronary heart disease. Tooth loss in people under 60 , however, is usually caused by dental caries." Thus, we cannot rule out the possibility that the increased risk of coronary heart disease among young men with no teeth may have been related to previous dental decay.

The essential question is whether the association between dental disease and coronary heart disease is causal. In the entire study population the associations, particularly with periodontal disease, were weak and may have been due to small biases or residual confounding. The associations we found in younger men, however, were stronger and could not be as readily dismissed. The reason for the stronger association in the younger men is not clear. Similar differences in relative risks between young and old have been observed in studies of other risk factors for coronary heart disease..$^{12-14}$

A limitation of our study is that we had baseline data on smoking for only a few of the subjects and could not completely control for the potentially confounding effects of cigarette smoking. In analyses restricted to subjects whose history of smoking was known, however, the results were compatible with the overall results. This indicates that residual confounding due to smoking is not likely to explain our findings.

Several factors minimised potential biases in the study. The dental examinations were performed before follow up for disease occurrence and thus there should have been little if any bias in the assessment of oral health. The hypothesis of an association between coronary heart disease and poor oral health was not part of the design or conduct of the original or follow up studies, which would further decrease possible information bias. Selection bias should also have been low because of the high rate of follow up.

For several reasons the retrieval of hospital records was not as complete as that of death certificates in the follow up study, ${ }^{9}$ and information on admission to hospital may not be as reliable as that for mortality. This may have affected the differences we found in relative risks between mortality and admission to hospital for coronary heart disease among the younger men. Young men with periodontitis had a nearly threefold increased risk of death from coronary heart disease but only about a $50 \%$ increased risk of admission to hospital for coronary heart disease. Possibly men with more severe periodontal disease have less access to, or less frequently use or recall use of, health 
care services. If this is the case, then our relative risks between periodontal disease and admission to hospital for coronary heart disease may underestimate the true risk.

The biological mechanism by which periodontal disease or poor oral hygiene could lead to coronary heart disease is not clearly established. The bacteria which cause periodontitis have been proposed as possible causative agents. ${ }^{1}$ Recent epidemiological studies have found that people with evidence of infection by Chlamydia pneumoniae have an increased risk of coronary heart disease. ${ }^{1516}$ The possibility that other bacteria, including those commonly associated with periodontal disease, may cause coronary heart disease is currently only theoretical. ${ }^{117} 18$

In conclusion, we found an association of coronary heart disease with periodontal disease and other measures of dental disease. Overall, the associations were weak, although not so weak in young men as to be dismissed as unimportant. Perhaps our most noteworthy finding, however, is that periodontal disease and poor oral hygiene are stronger indicators of risk of total mortality than of coronary heart disease. Oral health may be a more general indicator of personal hygiene and health care practices, including access to and use of health care services.

Dr Philip Graitcer provided valuable advice on the analysis plan.

1 Mattila KJ, Bieminen MS, Valtonen VV, Rasi RP, Kesaniemi YA, Syrajal $\mathrm{SL}$, et al. Association between dental health and acute myocardial infarction. BMF 1989;298:779-81.

2 Pooling Project Research Group. Relationship of blood pressure, serum cholesterol, smoking habit, relative weight and ECG abnormalities to incidence of major coronary events: final report of the pooling project. incidence of major coronary events. finat

3 National Center for Health Statistics. Decayed, missing, and filled teeth among persons 1-74 years: United States. Data from the National Health Survey. Hyattsville, Maryland: National Center for Health Statistics, 1981. (DHHS publication No (PHS)81-1673. Vital and health statistics; series 11; No 223.) 4 National Institute of Dental Research. Oral health of United States adults, the national survey of oral health in US employed adults and seniors: 1985-86. Bes Bethesda, Maryland: National

5 Gilmour H, Day E, Northridge

infarction. $B M 7$ 1989;298:1579-80. Mattila KJ. Dental health and acute myocardial infarction. BMf 1989;298: 1580

7 National Center for Health Statistics. Plan and operation of the health and nutrition examination survey: United States-1971-1973. Washington, DC: US GPO, 1977. (DHEW publication No (HRA) 77-1310. Vital and health statistics; series 1; No 10b.)

8 National Center for Health Statistics. Plan and operation of the NHANES I epidemiologic fellow-up study United States-1982-84. Washington, DC: US GPO, 1987. (DHHS publication No (PHS) 87-1324. Vital and health statistics; series 1; No 22.)

9 Madans JH, Kleinman JC, Cox CS, Barbano HE, Feldman JJ, Cohen B, et al. 10 years after NHANES I: report of initial follow up, 1982-84. Public Health Rep 1986;101:465-73.

10 Hopkins A. Survival analysis with covariates-Cox models. In: Dixon WJ, ed. BMDP statistical software manual. Los Angeles: University of California Press, 1988:719-44.

11 Miyazaki H, Pilot T, Leclercq M-H, Barmes DE. Profiles of periodontal conditions in adults measured by CPITN. Int Dent $f$ 1991;41:74-80.

12 DeStefano F, Ford ES, Newman J, Stevenson JM, Wetterhall SF, Anda RF, et al. Risk factors for coronary heart disease mortality among persons with diabetes. Ann Epidemiol 1993;3:27-34.

13 Stokes J III, Kannel WB, Wolf PA, Cupples LA, D'Agostino RB. The relative importance of selected risk factors for various manifestations of cardiovascular disease among men and women 35 to 64 years old: 30 years of following up in the Framingham study. Circulation 1987;75 (suppl V):65-73.

14 Posner BM, Cobb JL, Belanger AJ, Cupples LA, D'Agostino RB, Stokes J III. Dietary lipid predictors of coronary heart disease in men. Arch Intern Med 1991;151:1181-7.

15 Thom DH, Grayston JT, Siscovick DS, Wang S, Weiss NS, Daling JR Association of prior infection with Chlamydia pneumoniae and angioAssociation of prior infection with Chlamydia pneumoniae and angio-

16 Saikku P, Leinonen M, Tenkanen L, Linnanmaki E, Ekman M, Manninen V, et al. Chronic Chlamydia pneumoniae infection as a risk factor for coronary heart disease in the Helsinki heart study. Ann Intern Med 1992;116:273-8.

17 Lopes-Virella MF, Virella G. Immunological and microbiological factors in the pathogenesis of atherosclerosis. Clin Immunol Immunopathol 1985;37: 377-86.

18 Mattila KJ. Viral and bacterial infections in patients with acute myocardial infarction. F Intern Med 1989;225:293-6.

(Accepted 16 December 1992)
Department of Public

Health Sciences, St

George's Hospital Medical

School, London SW17 0RE

A Esmail, senior registrar

London E3 5AP

S Everington, general

practitioner

Correspondence to:

Dr A Esmail, Department of General Practice, University of Manchester, Rusholme

Health Centre, Manchester M14 5NP.

$B M \mathcal{F}$ 1993;306:691-2

\section{Racial discrimination against doctors from ethnic minorities}

\section{A Esmail, $S$ Everington}

A retrospective study of 1500 doctors graduating from five British medical schools between 1981 and 1987 suggested that those from ethnic minorities experienced disproportionate difficulty in obtaining hospital posts. ${ }^{\prime}$ A report published by the Commission for Racial Equality in 1987 also suggested that British trained doctors from ethnic minorities had trouble in getting the best jobs. ${ }^{2}$ Definitive evidence of discrimination, however, may be obtained only from a prospective study.

\section{Subjects, methods, and results}

A pilot study was carried out to test the hypothesis that British trained doctors with foreign sounding names were less likely to be shortlisted. We developed a curriculum vitae (CV) for six equivalent applicantsthree with Asian names and three with English names. All applicants were male, the same age, and educated and trained in Britain, with a similar length of experience in district general or teaching hospitals. All were at the same stage of their career, applying for their first senior house officer post in a non-teaching hospital because applications to teaching hospitals usually require completion of a form. Each $\mathrm{CV}$ was tailored to a particular post by including a short paragraph explaining why the candidate was applying for the job. The medical school and secondary education were randomly changed so that shortlisting was not influenced by attendance at a particular school or university. The pairs of names used for each application were randomly selected from the panel of three Asian and English applicants. The comparability of the CVs was confirmed by two consultants who were unaware of the purpose of the research and were asked to rate the CVs after the names had been removed.

Matched pairs of applications were sent for each post - one with an English name and one with an Asian name. The main outcome measure was the difference in the applicants' frequency of being shortlisted. When applicants were shortlisted we immediately cancelled any interviews.

We sent 46 applications for 23 advertised posts in otolaryngology, paediatric medicine, general surgery, psychiatry, and geriatric medicine. Eighteen applicants were shortlisted, of whom 12 had English and six Asian names (11 English and 17 Asian applicants were not shortlisted). In one post the English applicant was shortlisted and was subsequently withdrawnafter which the Asian applicant was shortlisted. This was included as a positive outcome for the English applicant.

The table shows the number of pairs where neither

Outcome of applications (pairs of English and Asian applicants shortlisted)

\begin{tabular}{|c|c|c|c|c|}
\hline & & \multicolumn{2}{|c|}{$\begin{array}{l}\text { English applicants } \\
\text { shortlisted }\end{array}$} & \multirow[b]{2}{*}{ Total } \\
\hline & & Yes & No & \\
\hline $\begin{array}{l}\text { Ethnic minority applicants } \\
\text { shortlisted }\end{array}$ & $\begin{array}{l}\text { Yes } \\
\text { No }\end{array}$ & $\begin{array}{l}6 \\
6\end{array}$ & $\begin{array}{r}0 \\
11\end{array}$ & $\begin{array}{r}6 \\
17\end{array}$ \\
\hline Total & & 12 & 11 & 23 \\
\hline
\end{tabular}

McNemar's test for matched pairs: $\chi^{2}=4 \cdot 17, p=0 \cdot 03, \mathrm{df}=1$ (with continuity correction). 